\title{
Entry and Exchanges of Cost Information.
}

\author{
Olivier Armantier* and Oliver Richard ${ }^{\dagger}$
}

August 2001

\begin{abstract}
The literature on exchanges of information has ignored firms' entry decisions. Yet, the Federal Trade Commission recently expressed concerns that exchanges of information in business-to-business electronic platforms would adversely impact entry and, thus, consumers. When entry decisions are endogenized in a competitive Cournot model with cost uncertainty, we find results that contrast sharply with current thinking on the welfare consequences of information sharing.
\end{abstract}

* Dept of Economics, SUNY Stony Brook NY, 11794. E-mail: olivier.armantier@sunysb.edu.

$\dagger$ Simon School of Business, University of Rochester, Rochester, NY 14627; E-mail: richard@ssb.rochester.edu. We are very grateful to Greg Shaffer and Greg Stoness for detailed, insightful comments on an earlier draft. We also thank seminar particpants at SUNY-Stony Brook and the University of Rochester for suggestions. 


\section{Introduction}

In 1994, the European Commission rejected an agreement to exchange information proposed by a tractor trade association in the U.K. on the ground that it raised barriers to entry and, thus, negatively impacted consumer welfare. ${ }^{1}$ The Federal Trade Commission recently expressed the same concerns regarding exchanges of information in business-tobusiness (hereafter B2B) electronic marketplaces. ${ }^{2}$ In their literature review for the European Commission, Kuhn and Vives (1995) report that, under Cournot competition and cost uncertainty, a complete sharing of cost information raises firms' profits, but is harmful to consumers in oligopoly structures with fewer than 10 firms. ${ }^{3}$ This literature, however, does not fully address the policy makers concerns since it ignores firms entry decisions.

When entry decisions are endogenized, we find results that contrast sharply with the existing literature. For instance, firms may not always have an incentive to exchange cost information. This result holds when an agreement to pool information encourages additional entry on the market which, in turn, lowers expected profits per firm. We also identify situations where firms decide not to share information, but nevertheless, social welfare would be improved by a cost sharing agreement. In such cases, policy-makers should therefore entice firms to exchange information. We then highlight that it may

\footnotetext{
${ }^{1}$ Decision from the European Commission dated February 17, 1992 and Court of First Instance Ruling dated October 27, 1994. Kuhn and Vives (1995) also outline the case.

${ }^{2}$ The October 2000 report entilted "Entering the 21st Century: Competition Policy in the World of B2B Electronic Marketplaces" is available on the Commission's web site.

${ }^{3}$ Vives (1999) provides a comprehensive summary of the literature. See, as well, Fried (1984), Gal-Or (1985, 1986), Malueg and Tsutsui (1998), Raith (1996), Sakai and Yamato (1989), Shapiro (1986), and Vives $(1984,1990)$.
} 
be possible to encourage this exchange without any monetary transfers. Finally, we find that, even if the number of entrants is the same whether or not firms exchange information, then consumers may benefit in market structures with as few as two firms. These results are significant, since policy makers typically consider consumer welfare to be the deciding factor in antitrust cases.

The paper is structured as follows. We describe the standard oligopoly model in Section 2 and generalize it slightly in Section 3. We then introduce the model with entry in Section 4 and analyze its implications. Section 5 concludes.

\section{The Standard Oligopoly Model}

Exchanges of cost information have usually been analyzed under a standard oligopoly model (hereafter SOM) originally proposed by Fried (1984), Shapiro (1986) and then extended by Sakai and Yamato (1989) and Raith (1996). We now summarize the main features of this model.

There are $N$ firms $(i=1, \ldots, N)$ competing on a single market, each producing a differentiated product. Let $x_{i}$ be the output of the $i^{\text {th }}$ firm, and $p_{i}$ its unit price. On the demand side, there is a representative consumer with the following quadratic utility function:

$$
U\left(x_{0}, x_{1}, \ldots, x_{N}\right)=x_{0}+a \sum_{i=1}^{N} x_{i}-\frac{1}{2}\left(\sum_{i=1}^{N} x_{i}^{2}+b \sum_{i=1}^{N} \sum_{j \neq i j}^{N} x_{j} x_{i}\right)
$$

where $x_{0}$ is the numeraire good, $a>0$ and $-1 /(n-1) \leq b \leq 1$. The representative 
consumer budget constraint is $x_{0}+\sum_{i=1}^{N} p_{i} x_{i}=m$, where $m$ is the consumer's income.

The corresponding optimization problem leads to the following system of inverse demand functions:

$$
p_{i}=a-x_{i}-b \sum_{j \neq i}^{N} x_{j} \quad \forall i=1, \ldots, N
$$

These demand functions are assumed to be common knowledge.

Marginal costs of production, $c_{i}(i=1, \ldots, N)$, are typically assumed to be jointly normally distributed with $E\left(c_{i}\right)=\mu>0, \operatorname{Var}\left(c_{i}\right)=\sigma^{2}, \operatorname{Cov}\left(c_{i}, c_{j}\right)=\rho \sigma^{2} \quad \forall i \neq j$ and $-1 /(n-1) \leq \rho \leq 1 .^{4}$ Marginal costs are assumed to be private information. In other words, each firm knows its own marginal cost but does not observe its rivals' ${ }^{5}$ The game consists of three stages:

- Stage 1: Firms jointly decide whether or not to enter a binding agreement to exchange cost information. Under this agreement, firms truthfully reveal to each other their cost vector $c_{i}$ at the beginning of stage 2 . It is assumed that firms can transfer and verify each other's reports at no cost and renegotiations after stage 1 are not allowed. ${ }^{6}$

- Stage 2: If all firms agreed to share information in stage 1, then each firm observes

\footnotetext{
${ }^{4}$ See, for instance, Fried (1984), Gal-Or (1986), Raith (1996), Shapiro (1986), Sakai and Yamato (1989), and Vives (1999). Note that the normality assumption is chosen in the literature because it yields affine conditional expectations (e.g. $E\left(c_{j} \mid c_{i}\right)=\rho\left(c_{i}-\mu\right)+\mu \quad \forall j \neq i$ ) and analytical tractability.

${ }^{5}$ In the context of the SOM, it is technically equivalent to have the constant marginal cost of production or a firm-specific demand intercept $\left(\alpha_{i}\right)$ be private values to the firm. Note that some models assume that firms only observe a noisy signal $\widetilde{c}_{i}=c_{i}+\varepsilon_{i}$ where $\varepsilon_{i}$ is an error term (see Raith (1996)).

${ }^{6}$ Okuno-Fujiwara et al. (1990) and Ziv (1993) show that firms may want to renegotiate their agreement to exchange information after learning their type. We assume that a time constraint associated with the approval of a cost sharing agreement by a regulatory commision prevents any renogotiation after stage 1 .
} 
the entire vector of marginal costs $\left(c_{1}, \ldots, c_{N}\right) .^{7}$ Otherwise, firm $i$ only observes its own marginal cost $c_{i}$. Given the information structure on costs, each firm then chooses its output level as to maximize its (expected) profits.

The model is solved using backward induction. In stage 3, the symmetric Nash equilibrium quantity produced by a firm under a cost sharing agreement (i.e., competition under complete information) is

$$
x_{i, s}^{*}\left(c_{i}\right)=\frac{a(2-b)-c_{i}(2+(n-2) b)+b \sum_{j \neq i}^{N} c_{j}}{(2+(n-1) b)(2-b)}
$$

On the other hand, when firms decide not to enter any agreement, they compete under incomplete information on marginal costs and produce at the equilibrium

$$
x_{i, n s}^{*}\left(c_{i}\right)=\frac{a}{2+(n-1) b}+\frac{(n-1) b}{4+2(n-1) b} \mu-\frac{c_{i}}{2}
$$

Raith (1996) show that firms' expected profits are larger under complete information. Then, the subgame perfect Nash equilibrium strategy is to agree to share cost information in stage 1 and to choose quantity in stage 3 according to equation (2.3).

The effect of cost sharing on consumers is not as straightforward. Sakai and Yamato (1989) show that there exist some pairs $(b, \rho) \in] 0,1[2$ such that the expected consumer surplus is larger under information sharing, but this is possible only if costs are correlated

\footnotetext{
${ }^{7}$ To our knowledge, only Shapiro (1986) analyzes information sharing among subset of firms. Given the hypothesis that products are perfect substitutes, he shows that all firms exchange cost information in equilibrium. Note, as well, that some authors assume that firms only observe a noisy version of their competitors marginal costs: $\widetilde{c}_{j}=c_{j}+\varepsilon_{i} \forall j \neq i$ where $\varepsilon_{i}$ is an error term (see Gal-Or (1986))
} 
and $N \geq 10$. In other words, information sharing is harmful to consumers in oligopoly structures with fewer than 10 firms. Finally, it has been established that cost information sharing always improves social welfare in the SOM.

\section{Comments and Generalization}

The SOM relies upon two implicit assumptions:

- Assumption A1: The number of firms on the market is fixed to $N$.

- Assumption A2: The number of firms on the market and the parameters of the model are such that the probability that firms produce non-positive equilibrium quantity is negligible. ${ }^{8}$

Assumption 1 implies that entry decisions are exogenous and, in particular, independent of any agreement to exchange information. In other words, the number of firms on the market is the same whether or not firms decide to exchange information. A consequence of Assumption 2 is that the model may be solved as if all firms are going to produce strictly positive quantities in equilibrium.

The objective of the present paper is to relax assumption 1 and to examine the effects of exchanges of cost information on entry decisions. However, in models with entry, the probability of firms producing negative equilibrium quantities cannot always be assumed negligible, since the number of firms varies endogenously. To see this,

\footnotetext{
${ }^{8}$ There exist parameters values such that the optimal strategies in (2.3) and (2.4) are negative.
} 
note that expected profits in both information structures are equal to $E\left[\left(x_{i, d}^{*}\left(c_{i}\right)\right)^{2}\right]$ and therefore they cannot be negative. Thus, the number of entrants may become unbounded when costs of entry become arbitrarily small. Consequently, the probability of negative equilibrium quantities cannot be ignored as it increases with the number of firms. Hence, we first generalize the SOM by adding a non-negativity constraint on quantities choices. ${ }^{9}$ We opted to add this constraint, as opposed to using a non-linear demand function, in order to stay consistent with the demand hypotheses of the SOM.

\subsection{A Generalized Standard Oligopoly Model}

In the private (or incomplete) information structure, firm $i$ now chooses a weakly positive output level so as to maximize its expected profits:

$$
x_{i, n s}^{*}\left(c_{i}\right)=\underset{x_{i}}{\operatorname{Arg} \max } E\left[\pi_{i, n s} \mid c_{i}\right]=E\left[\left(p_{i}-c_{i}\right) x_{i} \mid c_{i}\right] \quad \text { subject to } \quad x_{i} \geq 0
$$

The corresponding symmetric Nash equilibrium quantities are given by:

$$
\begin{gathered}
x_{i, n s}^{*}\left(c_{i}\right)=\frac{1}{2}\left(a-b(n-1) E\left[x^{*} \mid c_{i}\right]-c_{i}\right) I_{\left\{c_{i} \leq \bar{c}\right\}} \quad \forall i=1, \ldots N \\
\text { where } \quad \bar{c}=a-b(n-1) E\left[x^{*} \mid \bar{c}\right] \quad,
\end{gathered}
$$

\footnotetext{
${ }^{9}$ Since the distribution of costs is unbounded, marginal costs and prices may also be negative. The probability of negative costs is negligible for an appropriate selection of parameters $(\mu, \sigma)$ and the results in section 3 and 4 generalize to any non-negative continuous distribution on costs. The resolution of the model under an additional non-negativity constraint on prices is truly non-trivial. In the subsequent numerical simulations, the parameters of the model are such that prices are always positive.
} 
$I_{\left\{c_{i} \leq \bar{c}\right\}}$ is the indicator function defined as $I_{\left\{c_{i} \leq \bar{c}\right\}}=1$ when $c_{i} \leq \bar{c}$ and $I_{\left\{c_{i} \leq \bar{c}\right\}}=0$ otherwise, $\bar{c}$ is a threshold cost value and $E\left[x^{*} \mid c_{i}\right]$ is the conditional expected equilibrium quantity of any competitor of player $i$. Note that firms only produce in equilibrium if their marginal cost is below the threshold cost $\bar{c}$.

When firms exchange information, the optimization problem is:

$$
x_{i, s}^{*}\left(c_{i}\right)=\underset{x_{i}}{\operatorname{Arg} \max } \pi_{i, s}=\left(p_{i}-c_{i}\right) x_{i} \quad \text { subject to } \quad x_{i} \geq 0
$$

which leads to the following equilibrium quantities:

$$
\begin{gathered}
x_{i, s}^{*}\left(c_{i}\right)=\left[\frac{\left(2+b\left(\sum_{j \neq i}^{N} I_{\left\{c_{j} \leq \bar{c}_{j}\right\}}-1\right)\right)\left(\bar{c}_{i}-c_{i}\right)}{(2-b)\left(2+b\left(\sum_{j=1}^{N} I_{\left\{c_{j} \leq \bar{c}_{j}\right\}}-1\right)\right)}\right] I_{\left\{c_{i}<\bar{c}_{i}\right\}} \\
\text { where } \quad \bar{c}_{i}=\frac{(2-b) a+b \sum_{j \neq i}^{N} c_{j} I_{\left\{c_{j} \leq \bar{c}_{j}\right\}}}{2+b\left(\sum_{j \neq i}^{N} I_{\left\{c_{j} \leq \bar{c}_{j}\right\}}-1\right)} \quad \forall i=1, \ldots, N
\end{gathered}
$$

The optimal solutions in both information structures are non-linear and they rely upon a system of implicit equations. We propose in the Appendix a general algorithm to determine numerically the constraint Nash equilibrium quantities. The object of this algorithm is to solve numerically the implicit equations defining the different $\bar{c}_{i}$ and to approximate the function $E\left[x^{*} \mid c_{i}\right]$ using simulations.

We find that the addition of a non-negativity constraint preserves firms' incentive to share information. We also find that when consumers benefit from information pooling 
in the SOM, they also benefit in the generalized SOM. More significantly, we identify instances where consumers benefit from information sharing in markets structures with as few as two firms, in sharp contrast with findings for the SOM (where we must have $N \geq 10$ for consumers to benefit).

To illustrate, consider the following examples where costs are jointly normally distributed, $a=10, \mu=10, \sigma^{2}=2$ and $N \in(2,10)$. Firms expected profits and consumer expected surplus in the standard and generalized models are compared for $(b, \rho) \in[0,1]^{2}$ in Graphs 1 to 2. Specific numerical results for $(N=2, b=0.5, \rho=0.95)$ and $(N=10, b=0.5, \rho=0.7)$ are summarized in Tables 1 and 2 . These results indicate that firms increase their expected profits by exchanging information, albeit the gains are slightly smaller (in absolute and relative terms) in our generalized model. The results also illustrate that consumers benefit from information sharing for a larger set of parameter values $(N, b, \rho)$ than implied by the SOM.

Heuristically, the change in information structure (from incomplete to complete information) in the SOM affects only the quantity produced by a firm. In the generalized SOM both the quantity produced and the probability that a firm is active are affected. ${ }^{10}$ Under appropriate values of $(b, \rho)$, a market may then be active more frequently under complete information which, in turn, may improve consumer welfare. For instance, in Table 1, although the probability that a given firm produces a positive quantity may be lower under complete information than with incomplete information, entry decisions are

\footnotetext{
${ }^{10} \mathrm{~A}$ firm is said to be active when it produces a strictly positive quantity in equilibrium. Likewise, a market is said to be active when at least one firm is active.
} 
less correlated. ${ }^{11}$

\section{The Model with Entry}

We now extend the traditional model to examine the effects of exchanges of information on entry decisions. The structure of the model is as follows:

- Stage 1: The $N$ firms simultaneously decide whether or not to enter into a binding agreement to exchange cost information.

- Stage 2: Each firm chooses whether or not to enter the market. If firm $i$ enters the market it incurs a fixed costs $F_{i}$. Fixed costs are assumed to be common knowledge and sunk upon entry.

- Stage 3: If the entrants agreed to share cost information in stage 1, then they observe the entire vector of marginal costs. Otherwise, each entrant observes only its own marginal cost. Then, given the information structure on costs, the firms simultaneously choose their output level, subject to the constraint that they produce a non-negative quantity. In other words, should a firm have a high marginal cost given the number of entrants, it may choose not to supply the market by selecting an output of zero.

The fixed costs may include foreseeable expenses associated with investments in capacity, R\&D, contract or licensing fees, and development of sales, supply, or distribution

\footnotetext{
${ }^{11}$ We define a variable $E N T R Y$ such that $E N T R Y_{i, j}=1$ when firm $i$ enters the market at simulation $j$ and $E N T R Y_{i, j}=-1$ otherwise.
} 
channels. These fixed costs may be incurred by new firms to enter the market or by incumbents to renew their activity. Marginal costs, on the other hand, are inherently affected by factors such as input prices, workers' productivity or unforeseen idiosyncratic events such as delays. In this context, a firm precisely observe its marginal cost only at the time of production.

The structure of this model characterizes R\&D intensive industries (e.g. semiconductors), industries with sunk capacity investments (e.g. steel), or industries where extensive marketing or distribution channels are necessary (e.g. airlines (see Kuhn and Vives (1995), automobile (see Doyle and Snyder (1999))). In these industries, trade associations and joint ventures have historically been the mediums for exchanges of information. In recent years however, B2B ecommerce internet platforms have both facilitated and widely expanded exchanges of information. The timing of our model is consistent with firms' practices and policy-makers' regulatory approach. For example, when the major auto-makers considered exchanging information on supply parts through a B2B internet marketplace (e.g. the Covisint project), they first announced publicly their intentions, then awaited for the Federal Trade Commission guarded approval before proceeding with foreseeable development costs. ${ }^{12}$

\footnotetext{
${ }^{12}$ Concise overviews of the Covisint decision can be found in "B2B Exchanges Get Yellow Antitrust Light" from the law firm Katten Muchin Zavis, available at www.kmz.com, and on Professor Jack M. Wilson website at www.jackmwilson.com/eBusiness/.
} 


\subsection{Exchanges of Information: Firms Incentives}

We now show that, in contrast to the findings for the SOM, firms may not find it profitable to exchange cost information in a model with entry.

Rank, without loss of generality, firms according to their fixed cost $F_{1} \leq F_{2} \leq$ $\ldots \leq F_{N}$. In stage 2 , firms have not yet observed their marginal cost. Hence, firms are symmetric and expected (variable) profits in stage 3, which are conditional upon the number of entrants and the information structure, are identical across firms. Let $E\left[\pi_{d} \mid n\right]$ denote a firm's conditional expected profits in stage 3 given information structure $d$, given $d \in\{s, n s\}$, and $n$ entrants. Then let $n_{d}^{*}=\sup _{1 \leq n \leq N}\left(n: E\left[\pi_{d} \mid n\right]-F_{n} \geq 0\right)$ be the number of firms that have non-negative net expected profits in stage 2 under information structure $d$.

As conditional expected profits in stage 3 strictly decline with the number $n$ of entrants, $n_{s}^{*}$ and $n_{n s}^{*}$ are uniquely defined. ${ }^{13}$ However, the identity of the $n_{q}^{*}$ entering firms need not be unique, as when firms $n_{q}^{*}$ and $n_{q}^{*}+1$ are such that one or the other (but not both) have positive expected profits in the presence of firms 1 to $\left(n_{q}^{*}-1\right)$. We assume that the identity of the firms in $n_{s}^{*}$ and $n_{n s}^{*}$ is unique and concentrate on the socially efficient Nash equilibrium in pure strategies. Under this solution concept, the firms that enter in the equilibrium are the ones with the smallest fixed costs.

We saw in Section 3 that, for a given number of firms, expected profits are higher under information sharing. It follows, from the definition of $n_{q}^{*}$, that the number of

\footnotetext{
${ }^{13}$ See Berry (1992) for a proof of this result.
} 
entrants in stage 2 is at least as large under an agreement to exchange information than under no agreement (i.e., $n_{s}^{*} \geq n_{n s}^{*}$ ). Hence, we need to consider three cases:

- (4.1.1) If $n_{s}^{*}=n_{n s}^{*}$, then firms exchange cost information.

If the number of entrants is the same under both information structures, then the model is similar to the generalized SOM developed in Section 3. In that Section, we found that, for a given number of firms, expected profits are higher under information sharing. Therefore, in the equilibrium, firms 1 through $n_{s}^{*}$ agree to exchange cost information in stage 1 and enter in stage 2 . They then choose quantities in stage 3 under complete information according to (3.3). Firms $n_{s}^{*}+1$ to $N$, meanwhile, stay out of the market in stage 2 , in which case their decision on an information exchange in stage 1 is inconsequential.

- (4.1.2) If $n_{s}^{*}>n_{n s}^{*}$ and $E\left[\pi_{s} \mid n_{s}^{*}\right]<E\left[\pi_{n s} \mid n_{n s}^{*}\right]$, then firms do not exchange cost information.

In (4.1.2), firms 1 through $n_{n s}^{*}$ are worst off, in expected terms, under an agreement to exchange information. Thus, in the equilibrium, (at least one of) these firms do not exchange cost information. ${ }^{14}$ Then, firms 1 through $n_{n s}^{*}$ enter in stage 2 and choose quantities in stage 3 under incomplete information according to (3.1). Meanwhile, firms $\left(n_{n s}^{*}+1\right)$ to $N$ stay out of the market in stage 2 .

\footnotetext{
${ }^{14}$ Allowing for subsets of entrants to exchange information may yield additional solutions in (4.1.2). Consider, for instance, a model with 3 firms such that $n_{s}^{*}=3$ and $n_{n s}^{*}=1$ and (4.1.2) holds. Then firm 1 (which has the lowest fixed cost) does not want to exchange information. Firms 2 and 3 may however agree to exchange with each other in which case, say, they enter. The equilibrium solution may then involve an exchange of information among the firms.
} 
To illustrate, consider the duopoly example in Table 1 with $F_{1}=0.16$ and $F_{2}=$ 0.163. We have that $n_{n s}^{*}=1$ since $E\left[\pi_{n s} \mid n_{n s}^{*}=2\right]=0.162<F_{2}$, and $n_{s}^{*}=2$ since $E\left[\pi_{s} \mid n_{s}^{*}=2\right]=0.166>F_{2}$. As $E\left[\pi_{s} \mid n_{s}^{*}=2\right]=0.166<0.25=E\left[\pi_{n s} \mid n_{n s}^{*}=1\right]$, firm 1 has higher expected profits if it does not exchange information. Hence, in the equilibrium solution, firms do not exchange information in stage 1 and only firm 1 enters in stage 2 . In stage 3 , it produces the monopoly output given its marginal cost.

- (4.1.3) If $n_{s}^{*}>n_{n s}^{*}$ and $E\left[\pi_{s} \mid n_{s}^{*}\right] \geq E\left[\pi_{n s} \mid n_{n s}^{*}\right]$, then firms exchange cost information.

In this instance, firms 1 through $n_{n s}^{*}$ are better off under an agreement to exchange information and the equilibrium solution is identical to that in (4.1.1).

\subsection{Exchanges of Information: Consumer Welfare}

Here, we show that consumers may benefit from exchanges of information across a wider range of market structures than implied by the SOM. We first consider the case where the number of entrants (in stage 2) is larger under information sharing.

- (4.2.1) If $n_{s}^{*}>n_{n s}^{*}$, then consumers may benefit from exchanges of information.

For example, in our duopoly example in Table 1 with $F_{1}=0.16$ and $F_{2}=0.163$, expected consumer surplus is higher with information sharing (i.e. 0.240 vs. 0.125 ). Note that consumers may benefit even when costs are uncorrelated, in contrast to findings in the SOM. For instance, assume that $\rho=0$ and $F_{2}=0.21$, but all other parameters are 
unchanged, in our duopoly example of Table 1 . Then $n_{n s}^{*}=1, n_{s}^{*}=2$, and expected consumer surplus is again higher with information sharing (i.e. 0.245 vs. 0.125 ).

- (4.2.2) If $n_{s}^{*}>n_{n s}^{*}$ and $E\left[\pi_{s} \mid n_{s}^{*}\right]<E\left[\pi_{n s} \mid n_{n s}^{*}\right]$, social welfare may be higher if firms were to exchange information.

In (4.2.2), firms do not exchange information since it reduces their expected profits and, thus, only firms 1 to $n_{n s}^{*}$ enter (see 4.1.2). If firms were to share information though, additional firms would enter and the increase in consumer surplus might more than compensate for firms' losses, so that social welfare would be higher. For instance, in our duopoly example with $F_{1}=0.16$ and $F_{2}=0.163$, social welfare would be higher if firms shared information (i.e. 0.33 vs. 0.215$).{ }^{15}$

This discussion suggests that policy-makers may want to entice firms to exchange information. Such incentives could be provided with lump-sum taxes on the consumer's income or on firms' profits. More significantly, such incentives may actually involve no monetary transfers in equilibrium. Suppose, in our duopoly example, that policymakers guarantee to provide a sum of 0.02 to firm 2 if it enters and does not exchange information. Then, if firms do not exchange information and firm 2 enters, it expects to earn net profits of $0.01=0.162+0.02-0.163$, in which case it enters. Since $n_{n s}^{*}=n_{s}^{*}=2$, it is now optimal for both firms to share information (see (4.1.1)), in which case firm 2 earns net expected profits of 0.03 (i.e., $-0.163+0.166$ ). Thus, the equilibrium solution

\footnotetext{
${ }^{15}$ Under information sharing, expected net profits are equal to $0.166 \times 2-0.163-0.16=0.09$ and expected consumer surplus is 0.24 , so that expected social welfare equals to 0.33 . Under no information sharing, expected social welfare is equal to $0.25-0.16+0.125=0.215$.
} 
has firms sharing information in stage 1. Both consumers and society benefit and, since firms share information, policy-makers never actually subsidize firm 2.

Finally, when information sharing does not affect the number of entrants (i.e., $n_{s}^{*}=$ $\left.n_{n s}^{*}\right)$, the consumer surplus analysis is equivalent to the one conducted in Section 3:

- (4.2.3) When $n_{s}^{*}=n_{n s}^{*} \geq 2$, consumers may benefit from information sharing for a larger set of parameters $(b, \rho) \in] 0,1{ }^{2}$ than the SOM suggests.

In particular, consumers may benefit from exchanges of information in market structures with as few as two firms.

\section{Conclusion}

We have shown that endogenizing entry decisions affects predictions regarding firms' decisions to share cost information and the effect of information sharing on consumer welfare. As illustrated in our discussion, firms may actually decide not to exchange information in a competitive Cournot model with cost uncertainty, even though such an exchange may improve consumer and social welfare. Hence, policy-makers may want to entice firms to share information. Such incentives could be provided through trade groups, B2B ecommerce platforms, or research consortia. We also showed that policymakers may not even need to make any monetary transfers or payments to induce firms to share information. In fact, we find that consumers may benefit from information sharing in a wide range of market structures, including oligopolies with few firms (e.g., duopolies). These results are significant, as they contrast, for instance, with current 
policy concerns regarding B2B exchanges. In particular, our analysis suggests that, pending a competitive marketplace, B2B exchanges encourage entry and, thereby, benefit consumers. Even if such exchanges do not expand the number of entrants, our findings indicate that they may make it more economical for firms to enter small markets that otherwise would be too expensive to supply. Indeed, as we documented in Section 3, firms more frequently supply a market where production costs are high when they compete under information sharing. ${ }^{16}$

\section{References}

Berry, S., 1992, Estimation of a Model of Entry in the Airline Industry, Econometrica 60, 889-917.

Doyle, M. and C. Snyder, 1999, Information Sharing and Competition in the Motor Vehicle Industry, Journal of Political Economy 107, 1326-1364.

Fried, D., 1984, Incentives for Information Production and Disclosure in a Duopolistic Environment, Quarterly Journal of Economics 99, 367-381.

Gal-Or, E., 1985, Information Sharing in Oligopoly, Econometrica, 329-343.

Gal-Or, E., 1986, Information Transmission - Cournot and Bertrand Equilibria, Review of Economic Studies 53, 85-92.

Kühn, K.U. and X. Vives, 1995, Information Exchange among Firms and their Impact on Competition, European Commission Document.

Malueg D. and S. Shunichi, Distributional Assumptions in the Theory of Oligopoly Information Exchange, International Journal of Industrial Organization 16, 785-797.

Okuno-Fujiwara M., Postlewaite A. and K.Suzumura, 1990, Strategic Information Revelation, Review of Economic Studies 57, 25-47.

Raith, M., 1996, A General Model of Information Sharing in Oligopoly, Journal of Economic Theory 71, 260-288.

\footnotetext{
${ }^{16}$ These results hold without even considering the cost efficiencies that have been associated with B2B exchanges (i.e., inexpensive access to sales channels, reduction in administrative and supplychain costs). In an interesting review of the Federal Trade Commission's workshops, Robert Ploch and Scott Perlman, partners at the law firm Mayer, Brown \& Platt in the area of antitrust, reach similar conclusions. Perlman was a member of the Commission's panel and the report is available at www.mayerbrown.com.
} 
Sakai, Y. and T. Yamato, 1989, Oligopoly, Information and Welfare, Journal of Economics (Zeitschrift für Nationalökonomie) 49, 3-24.

Shapiro, C., 1986, Exchange of Cost Information in Oligopoly, Review of Economic Studies 53, 433-446.

Vives, X., 1999, Oligopoly Pricing: Old Ideas and New Tools (MIT press).

Ziv A., 1993, Information Sharing in Oligopoly: The Truth-Telling Problem, Rand Journal of Economics 24, 455-465 


\section{Tables and Graphs}

\begin{tabular}{|c|c|c|c|c|c|c|c|c|c|c|c|c|}
\hline \multicolumn{13}{|c|}{ TABLE 1 : TWO FIRMS } \\
\hline & & \multicolumn{3}{|c|}{ Quantity } & \multicolumn{3}{|c|}{ Profit } & \multicolumn{3}{|c|}{ Entry } & \multicolumn{2}{|c|}{$\begin{array}{c}\text { Consumer } \\
\text { Surplus }\end{array}$} \\
\hline & & Mean & Var & Cov & Mean & Var & Cov & Proba & Var & $\mathrm{Cov}$ & Mean & Var \\
\hline \multirow{2}{*}{$\begin{array}{c}\text { With } \\
\text { Constraint } \\
\end{array}$} & C.I & 0.227 & 0.114 & 0.095 & 0.166 & 0.138 & 0.111 & 0.483 & 0.999 & 0.728 & 0.240 & 0.525 \\
\hline & I.I & 0.226 & 0.111 & 0.104 & 0.162 & 0.133 & 0.111 & 0.448 & 0.997 & 0.789 & 0.238 & 0.532 \\
\hline \multirow{2}{*}{$\begin{array}{c}\text { Without } \\
\text { Constraint }\end{array}$} & C.I & 0.002 & 0.334 & 0.290 & 0.334 & 0.222 & 0.167 & 1 & 0 & 0 & 0.479 & 0.661 \\
\hline & I.I & 0.003 & 0.326 & 0.310 & 0.326 & 0.215 & 0.170 & 1 & 0 & 0 & 0.481 & 0.674 \\
\hline
\end{tabular}

C.I and I.I respectively stand for Complete Information and Incomplete Information.

\begin{tabular}{|c|c|c|c|c|c|c|c|c|c|c|c|c|}
\hline \multicolumn{13}{|c|}{ TABLE 2 : TEN FIRMS } \\
\hline & & \multicolumn{3}{|c|}{ Quantity } & \multicolumn{3}{|c|}{ Profit } & \multicolumn{3}{|c|}{ Entry } & \multicolumn{2}{|c|}{$\begin{array}{c}\text { Consumer } \\
\text { Surplus }\end{array}$} \\
\hline & & Mean & Var & Cov & Mean & Var & Cov & Proba & Var & Cov & Mean & Var \\
\hline \multirow{2}{*}{$\begin{array}{c}\text { With } \\
\text { Constraint } \\
\end{array}$} & C.I & 0.114 & 0.055 & 0.008 & 0.068 & 0.044 & 0.003 & 0.314 & 0.862 & 0.154 & 0.799 & 1.257 \\
\hline & I.I & 0.096 & 0.025 & 0.016 & 0.034 & 0.02 & $1.1 \mathrm{D}-4$ & 0.398 & 0.958 & 0.472 & 0.762 & 1.706 \\
\hline \multirow{2}{*}{$\begin{array}{c}\text { Without } \\
\text { Constraint }\end{array}$} & C.I & $7.1 \mathrm{D}-4$ & 0.275 & 0.008 & 0.274 & 0.15 & $5.5 \mathrm{D}-4$ & 1 & 0 & 0 & 1.550 & 1.372 \\
\hline & I.I & 0.001 & 0.075 & 0.053 & 0.076 & 0.039 & 0.001 & 1 & 0 & 0 & 1.564 & 2.139 \\
\hline
\end{tabular}

C.I and I.I respectively stand for Complete Information and Incomplete Information. 


\section{GRAPH 1 : 2 PLAYERS}

\section{Consummer Surplus}

(Positive Values in Red)
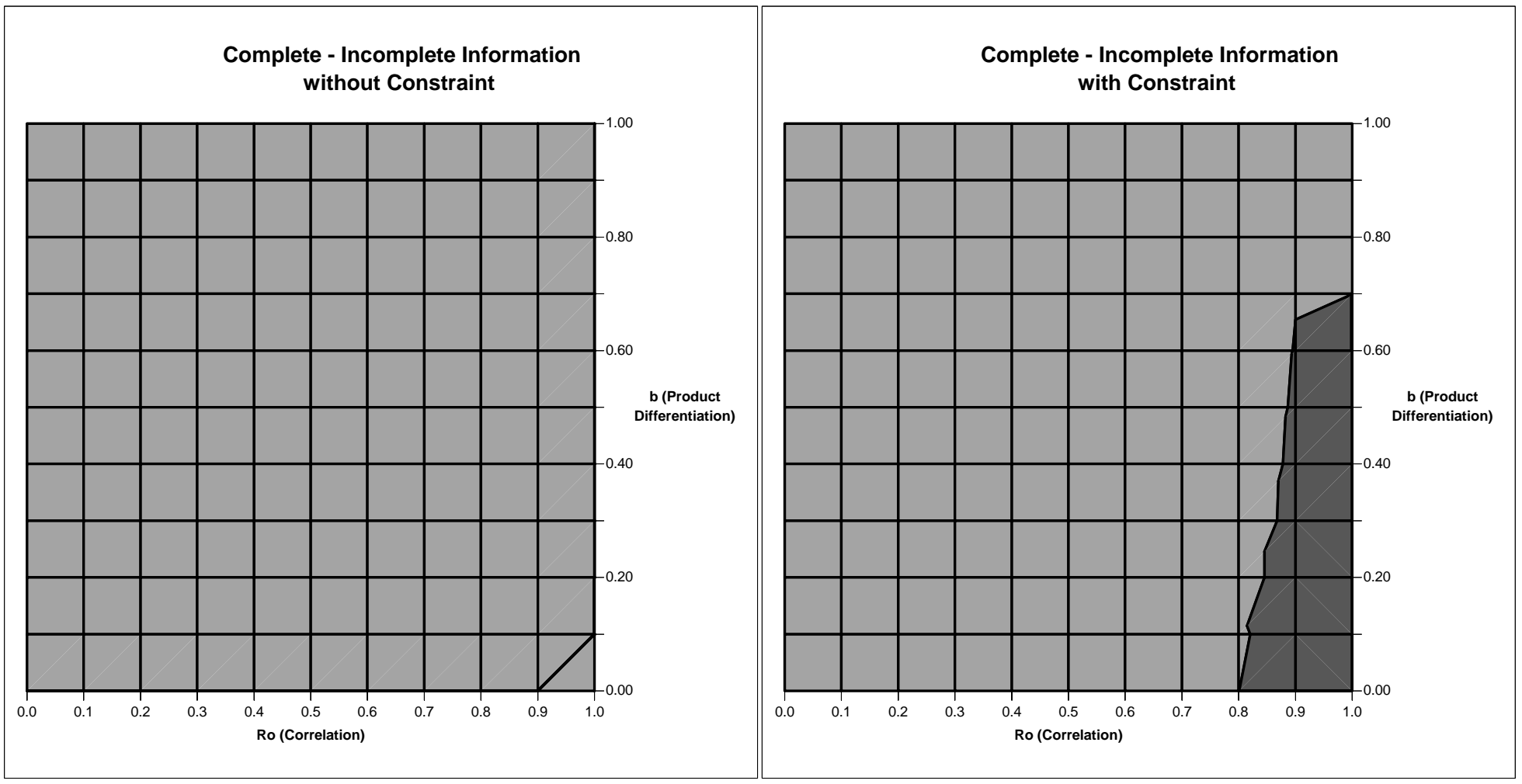

\section{Firms Profits}
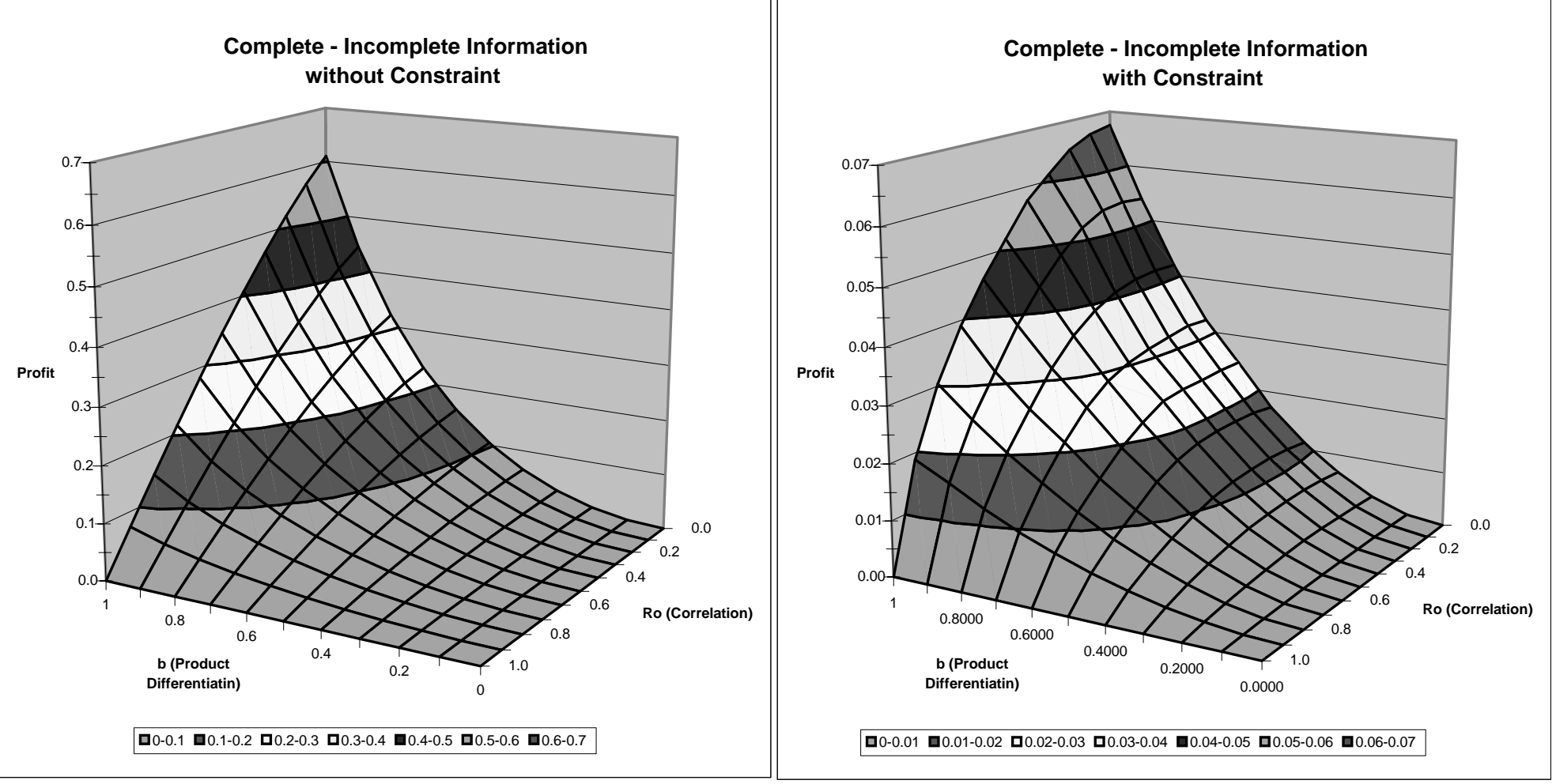


\section{GRAPH 2 : 10 PLAYERS}

\section{Consumer Surplus}

(Positive Values in Red)
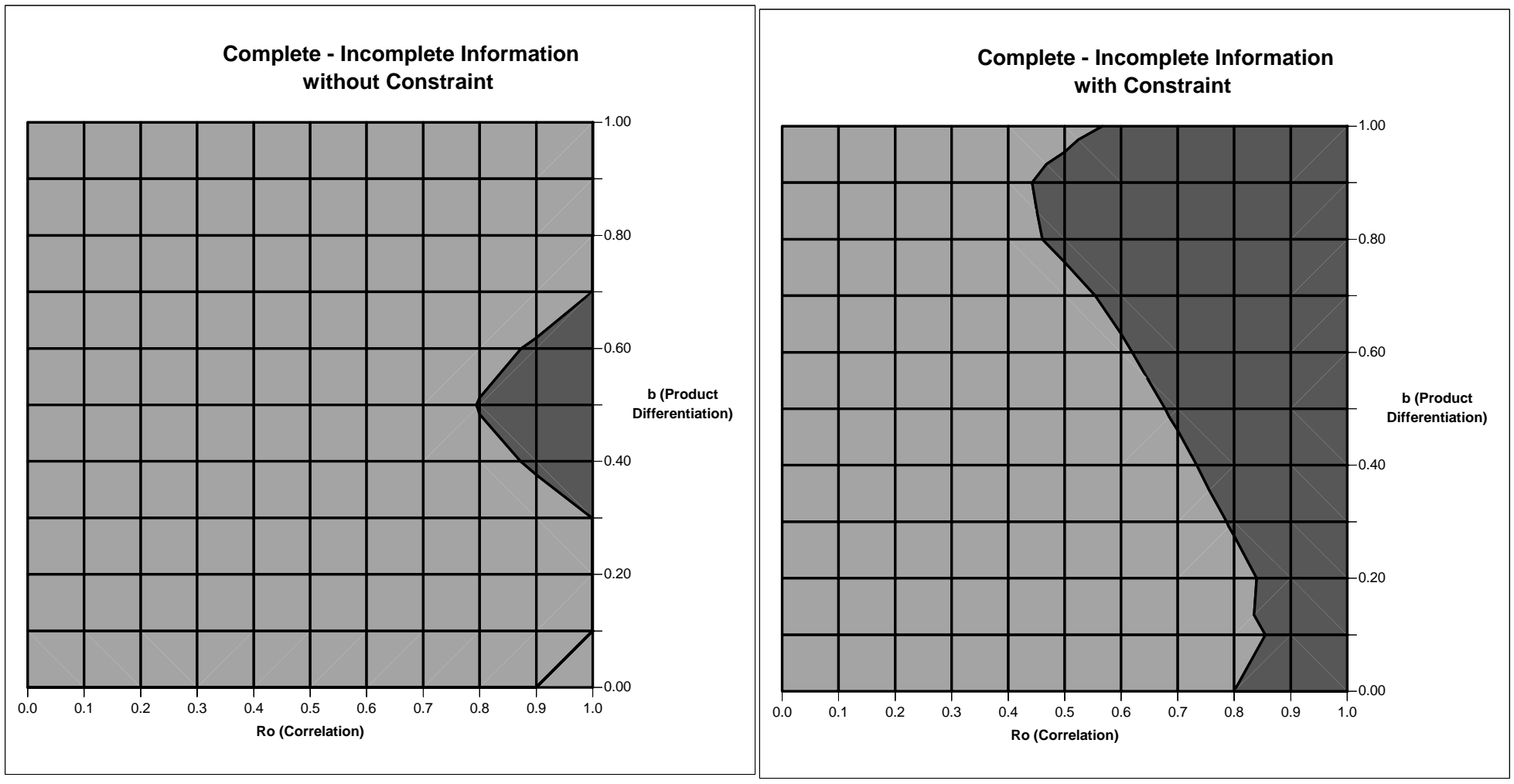

\section{Firms Profits}
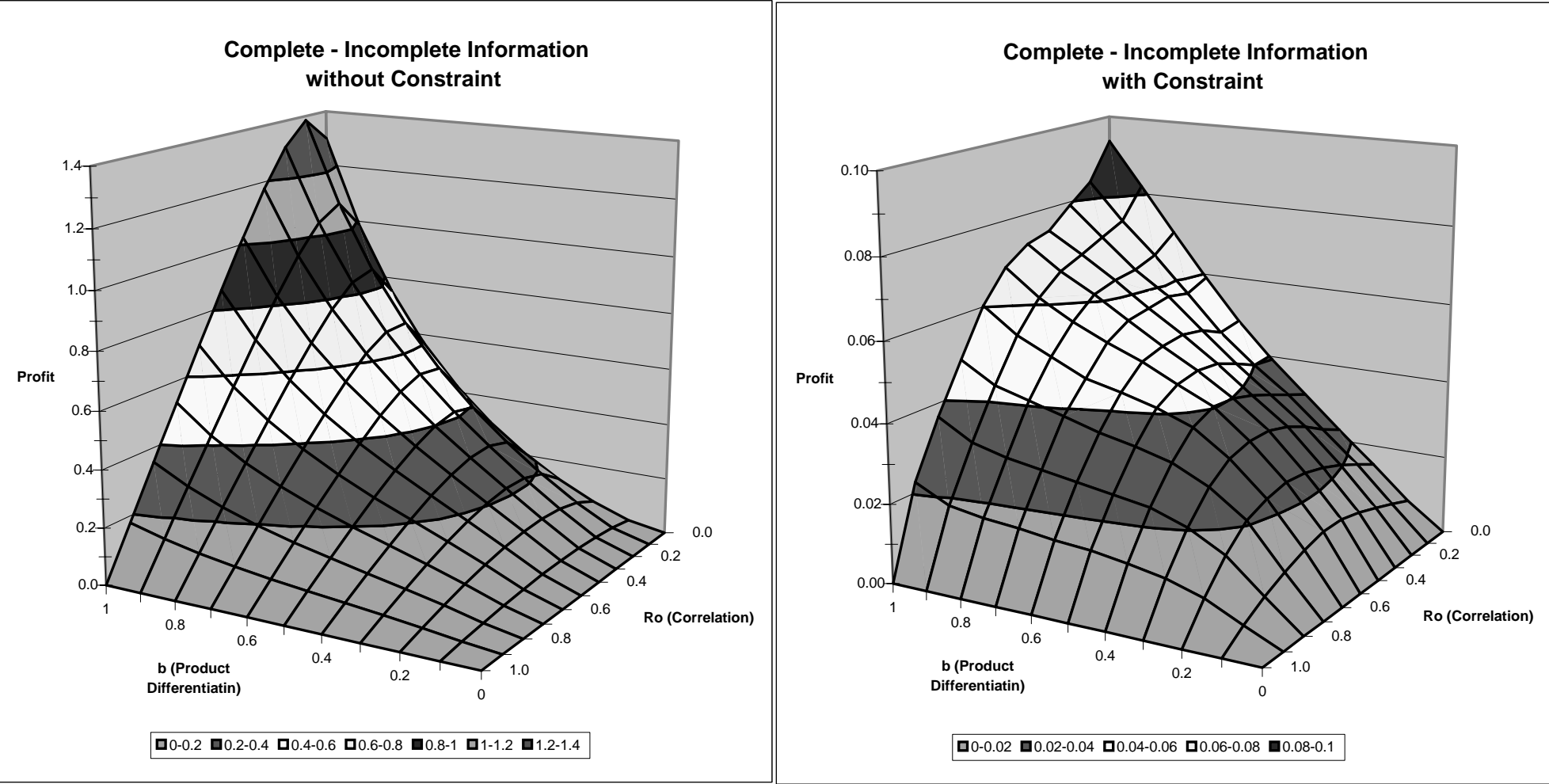


\section{Appendix: Determining Equilibrium Quantities.}

The numerical determination of the complete information problem is straightforward. We use standard numerical procedures to solve the system of non-linear equations (3.4) leading to the threshold $\operatorname{costs} \bar{c}_{i}$. Then, we can determine the equilibrium quantities by substituting $\bar{c}_{i}$ in (3.3).

To determine equilibrium quantities in the incomplete information model, we need to solve the system of equations (3.2) and then (3.1). Note that (3.1) depends upon the function $E\left[x(c) \mid c_{i}\right]$. In this case, unlike a complete information setting, firms cannot predict the exact quantities that their rivals produce at the Nash solution. To determine their best strategies, firms can rely only upon their rivals' conditional expected quantities, $E\left[x(c) \mid c_{i}\right]$. There is no analytically tractable way, however, to calculate the function $E\left[x(c) \mid c_{i}\right]$ at any point $c_{i}$.

We propose to replace this function by an approximation $f\left(c_{i}, \beta\right)$ parametrized by a vector $\beta$. Intuitively, $f(., \beta)$ is the fixed point solution of a problem matching a potential expected quantity to its empirical counterpart as calculated across Monte Carlo simulations. The algorithm proceeds as follows:

We simulate $S$ private types (using the Common Random Number technique) for the representative firm, $\left\{\widetilde{c}_{s}\right\}_{s=1, \ldots, S}$, from a normal distribution with mean $\mu$ and variance $\sigma^{2}$. For each value $\widetilde{c}_{s}$, we then simulate $K$ conditional private types, $\left\{\widetilde{c}_{s, k}\right\}_{k=1, \ldots, K}$, from

a normal distribution with mean $\mu(1-\rho)+\rho \widetilde{c}_{s}$ and variance $\sigma^{2}(1-\rho)^{2}$. Therefore, $\widetilde{c}_{s, k}$ may be interpreted as the private cost of an opponent of firm $i$, conditional on the fact 
that firm $i$ has a cost $\widetilde{c}_{s}$.

The determination of the approximation $f(., \beta)$ proceeds in several steps. First, for a given approximation of the conditional expectation $(f(., \beta))$ we find $\bar{c}\left(\widetilde{c}_{s, k}\right)$ and $\widetilde{x}\left(\widetilde{c}_{s, k} \mid \widetilde{c}_{s}\right)$ for any $\widetilde{c}_{s, k}$ by solving numerically equations (3.2) and (3.1). Next, we calculate the conditional empirical mean $\widehat{E}\left[x(c) \mid \widetilde{c}_{s}\right]$ of the quantity produced by an opponent of firm $i$, when firm $i$ has a cost $\widetilde{c}_{s}$. The object of the algorithm is then to find $\beta$ such that $f\left(\widetilde{c}_{s}, \beta\right)$ is arbitrarily close to $\widehat{E}\left[x(c) \mid \widetilde{c}_{s}\right]$ for any $\widetilde{c}_{s}$. In other words, the approximation $f(., \beta)$ is the solution of

$$
\begin{aligned}
& \min _{\beta} \sum_{s=1}^{S}\left\|f\left(\widetilde{c}_{s}, \beta\right)-\widehat{E}\left[x(c) \mid \widetilde{c}_{s}\right]\right\| \quad \text { where } \\
& f\left(\widetilde{c}_{s}, \beta\right) \text { is a piecewise linear function with parameters } \beta \in \Re^{l}, \\
& \widehat{E}\left[x(c) \mid \widetilde{c}_{s}\right]=\frac{1}{K} \sum_{k=1}^{K} \widetilde{x}\left(\widetilde{c}_{s, k} \mid \widetilde{c}_{s}\right), \\
& \widetilde{x}\left(\widetilde{c}_{s, k} \mid \widetilde{c}_{s}\right)=\frac{1}{2}\left(a-b(n-1) f\left(\widetilde{c}_{s, k}, \beta\right)-\widetilde{c}_{s, k}\right) I_{\left\{\widetilde{c}_{s, k}<\bar{c}\left(\widetilde{c}_{s, k}\right)\right\}} \\
& \bar{c}\left(\widetilde{c}_{s, k}\right)=a-b(n-1) f\left(\widetilde{c}_{s, k}, \beta\right) .
\end{aligned}
$$

In practice, $K=10^{4}, S=10^{6}, l=5$, and the precision for the minimization problem in (7.1) is of order $10^{-9}$. Once $f(., \beta)$ has been determined, we can calculate the equilibrium quantities for a given cost vector $c$. 